\title{
Genotypes and Haplotypes in the AXIN2 and TCF7L2 Genes are Associated With Susceptibility and With Clinicopathological Characteristics in Breast Cancer Patients
}

M. A. Rosales-Reynoso ${ }^{1 *}$, V. Rosas-Enríquez ${ }^{2}$, A. M. Saucedo-Sariñana ${ }^{1}$, M. Pérez-Coria ${ }^{1}$, M. P. Gallegos-Arreola ${ }^{3}$, E. Salas-González ${ }^{2}$, P. Barros-Núñez ${ }^{4}$, C. I. Juárez-Vázquez ${ }^{5}$, S. E. Flores-Martínez ${ }^{1}$ and J. Sánchez-Corona ${ }^{1}$

${ }^{1}$ Division of Molecular Medicine, Center for Western Biomedical Research (CIBO), Guadalajara, Mexico, ${ }^{2}$ Service of Medical Oncology, High Specialty Medical Unit, Hospital of Gynecology and Obstetrics, Guadalajara, Mexico, ${ }^{3}$ Division of Genetics, Center for Western Biomedical Research (CIBO), Guadalajara, Mexico, ${ }^{4}$ Unit of Follow-up Research of Metabolic Diseases, UMAE Pediatrics, Centro Médico Nacional de Occidente (CMNO), Instituto Mexicano del Seguro Social (IMSS), Guadalajara, Mexico, ${ }^{5}$ Academic Directorate Devices and Systems I, Faculty of Medicine, Dean of Health Sciences, Autonomous University of Guadalajara (UAG), Guadalajara, Mexico

Background: Breast cancer is a multifactorial disease whose genetic susceptibility is related to polymorphic variants of cell proliferation and migration pathways. Variants in

OPEN ACCESS

${ }^{*}$ Correspondence:

M. A. Rosales-Reynoso mareynoso77@yahoo.com.mx

Received: 10 November 2021 Accepted: 23 December 2021 Published: 25 January 2022

Citation:

Rosales-Reynoso MA Rosas-Enríquez V,

Saucedo-Sariñana AM, Pérez-Coria M, Gallegos-Arreola MP, Salas-González E, Barros-Núñez $P$, Juárez-Vázquez Cl, Flores-Martínez SE and Sánchez-Corona J (2022)

Genotypes and Haplotypes in the AXIN2 and TCF7L2 Genes are Associated With Susceptibility and

With Clinicopathological Characteristics in Breast Cancer Patients.

Br J Biomed Sci 79:10211. doi: 10.3389/bjbs.2021.10211 AXIN2 and TCF7L2 in the Wnt- $\beta$ catenin pathway have been associated with different types of cancer; however, little is known about its role in breast cancer. This study tests the hypothesis of links between AXIN2 rs1133683 and rs2240308, and TCF7L2 rs7903146 and rs12255372 variants in breast cancer.

Methods: Peripheral blood samples were obtained from 404 women (202 patients and 202 control females). The polymerase chain reaction-restriction fragment length polymorphism (PCR-RFLP) methodology was used to identify the gene variants.

Results: The AXIN2 rs2240308 (C > T), and TCF7L2 rs7903146 (C > T) and rs12255372 $(G>T)$ variants were associated with breast cancer and with age, TNM stage, and histologicmolecular subtype $(p=0.001)$. Likewise, the haplotype T-T in the TCF7L2 gene (rs7903146rs12253372) was significantly related with breast cancer $(\mathrm{OR}=2.66,95 \%, \mathrm{Cl}=1.64-4.30$, $p=0.001$.

Conclusion: Our data show a link between AXIN2 rs2240308 and TCF7L2 rs7903146 and rs12255372 variants in breast cancer, and speculate this may be important in pathogenesis.

Keywords: breast cancer, AXIN2, TCF7L2, genotypes, haplotypes, susceptibility 


\section{INTRODUCTION}

The World Health Organization highlight that breast cancer constitutes a significant worldwide health problem and is the leading cause of death among women (1). The estimated number of women with breast cancer in 2018 was 651,000, accounting for more than a third of worldwide cancer cases (2). However, survival rates among breast cancer patients in the developed world are much higher than those in less developed countries (3). Breast cancer is a complex disease influenced by a variety of factors, including the low education level, smoking, the environment, family history, obesity, hormones, and the immune system (4). Genetic risk factors also play essential roles in breast cancer development, including the most critical genes as $B R C A 1 / 2$ (5). Despite that only $5-6 \%$ of breast cancer cases are inherited, genetic mutations are among the most predictable risk factors contributing to breast cancer development (6).

Analyses of gene expression profile and genome-wide sequencing have demonstrated that the canonical $\mathrm{Wnt} / \beta$ catenin pathway is involved in processes of breast cancer initiation, proliferation, and metastasis (7). The Wnt signaling is a highly conserved pathway that regulates cellular processes including cell fate determination, organ development, polarity, motility, normal adult homeostasis, stem cell renewal and cancer $(8,9)$. Activation of Wnt pathway target genes depends on the recruitment of $\beta$ catenin into the nucleus. The interaction of TCF/LEF with the $\beta$-catenin protein results in the activation of a transcription complex that regulates the expression of target genes participating in tumorigenesis, such as CCND1, PPARD, ATOH1, CD44, FGF20, JAG1, LGR5, MYC, and SNAI1 (9-11). Among genes participating in this signaling pathway, AXIN2 and TCF7L2 have shown an association with different cancers. The AXIN2 gene is located on the long arm of chromosome 17q24 and encodes to the Axin2 protein, which participates as a negative regulator of the Wnt/ $\beta$-catenin pathway, exhibiting a crucial role in cell differentiation, migration, and apoptosis (12). The transcription factor 7-like 2 (TCF7L2) gene is located on chromosome 10q25.2, encodes a high mobility group (HMG) box-containing transcription factor involved in cell differentiation and migration (13). Therefore, mutations or variations in the Wnt signaling pathway components triggers the expression of numerous target genes involved in cellular proliferation, evasion of apoptosis, tissue invasion, and metastasis $(13,14)$.

Several studies have investigated the association of the AXIN2 and TCF7L2 polymorphisms with cancer. The AXIN2 polymorphisms have been associated with colorectal $(15,16)$, lung $(17,18)$, prostate (19), and breast cancer (20-23). Specifically, the AXIN2 rs2240308 (C > T) variant has been assessed and associated with several cancers (15-20); for breast cancer, this variant have been studied only in two different populations, although with inconsistent results $(20,22)$. For the variants rs7903146 $(\mathrm{C}>\mathrm{T})$ and $\operatorname{rs} 12255372(\mathrm{G}>\mathrm{T})$ of the TCF7L2 gene, various studies have been conducted in colorectal (24-28), prostate (29), lung (30), and breast cancer (31-34). In breast cancer, these variants show contradictory results among different populations.

We hypothesis that the distribution of alleles, genotypes, and haplotypes of the rs1133683 and rs2240308 variants of the AXIN2, and the rs7903146 and rs12255372 variants of the TCF7L2, are linked to major clinicopathological characteristics of breast cancer.

\section{MATERIALS AND METHOD}

A total of 404 women were recruited, 202 patients with clinical and histological diagnosis of breast cancer, according to the criteria of the UMAE Gynecology Hospital of the Social Security Mexican Institute (IMSS) in Guadalajara, Mexico. Breast cancer was stratified according to the tumor-nodemetastasis (TNM) classification. The control group was 202 unrelated healthy women age-matched with the patient group. The study was approved by the Ethical Committee 1305 (R2018-1305-004) of West Biomedical Research Center, IMSS, and conducted according to national and international ethical standards. All the participants signed informed consent for participation in this study. A standard epidemiological questionnaire allowed us to collect personal data, including age, gender, drinking and smoking status, familial history, and pharmacological therapy. Women with a previous cancer history were excluded from the control group, while those who had undergone chemotherapy or radiotherapy were excluded from the patient group. Information about the clinical and pathological features of the patients was obtained from the hospital records.

Genomic DNA was extracted from peripheral blood using standard methods (35). The polymorphisms (c.148C>T) rs2240308 and (c.1386C>T) rs1133683 in the AXIN2 gene and rs7903146 (C > T) and rs12255372 (G > T) in the TCF7L2 gene were genotyped by polymerase chain reaction-restriction fragment length polymorphism (PCR-RFLP) using the primer pairs described $(18,36)$. PCR for the rs2240308 polymorphism was performed through 30 cycles in a $10-\mu \mathrm{L}$ volume containing $100 \mathrm{ng} \mathrm{DNA}, 10 \mathrm{X}$ buffer $(500 \mathrm{mM} \mathrm{KCl}$, $100 \mathrm{mM}$ Tris- $\mathrm{HCl}$, and $0.1 \%$ Triton TMX-100), $2.0 \mathrm{mM}$ $\mathrm{MgCl} 2,200 \mu \mathrm{M}$ dNTPs, $1 \mathrm{pM}$ of each primer, and $2 \mathrm{U}$ Taq DNA Polymerase. Denaturation was carried out at $94^{\circ} \mathrm{C}$, annealing at $60^{\circ} \mathrm{C}$, and elongation at $72^{\circ} \mathrm{C}$ for $1 \mathrm{~min}$ each. Five microliters of the PCR product were digested with $3 \mathrm{U}$ of the NsiI restriction enzyme. The digested products were separated on $6 \%$ polyacrylamide gels. Fragment observed by electrophoresis corresponded to 218 and $24 \mathrm{bp}$ for the wild-type allele (C) and $242 \mathrm{bp}$ for the polymorphic allele (T). The rs1133683 polymorphism was identified under the same PCR conditions mentioned above. $4 \mathrm{U}$ of the restriction enzyme TaqI were used to digest $5 \mu \mathrm{L}$ of PCR products. The digested products were separated by electrophoresis on $8 \%$ polyacrylamide gels. Fragments of $294 \mathrm{bp}$ identify the wild-type allele (C), while fragments of 274 and $20 \mathrm{bp}$ correspond to the polymorphic allele $(\mathrm{T})$. Quality control 
TABLE 1 | Clinicopathological data of breast cancer patients.

\begin{tabular}{|c|c|}
\hline Characteristics & $\begin{array}{c}\text { Breast cancer group } \\
\qquad n=202(\%)\end{array}$ \\
\hline Body Mass Index (BMI) mean & $29.1( \pm 5.6)$ \\
\hline \multicolumn{2}{|l|}{ Menopause status } \\
\hline Pre-menopause & $51(25.2)$ \\
\hline Menopause & $151(74.8)$ \\
\hline \multicolumn{2}{|l|}{ Breastfeeding } \\
\hline No & $44(21.8)$ \\
\hline \multicolumn{2}{|l|}{ Yes } \\
\hline$<6$ months & $30(14.8)$ \\
\hline$>6$ months & $128(63.4)$ \\
\hline \multicolumn{2}{|l|}{ Hysterectomy } \\
\hline Yes & $42(20.8)$ \\
\hline No & $160(79.2)$ \\
\hline \multicolumn{2}{|l|}{ TNM stage } \\
\hline 1 & $10(4.9)$ \\
\hline$\|$ & $61(30.2)$ \\
\hline III & $59(29.2)$ \\
\hline IV & $72(35.7)$ \\
\hline \multicolumn{2}{|l|}{ Tumor location } \\
\hline Unilateral & $193(95.5)$ \\
\hline Left & $112(55.5)$ \\
\hline Right & $81(40.0)$ \\
\hline Bilateral & $9(4.5)$ \\
\hline \multicolumn{2}{|l|}{ Histology (adenocarcinoma) } \\
\hline Ductal & $176(87.1)$ \\
\hline Lobular & $24(11.9)$ \\
\hline Mixed & $2(1.0)$ \\
\hline \multicolumn{2}{|l|}{ Molecular subtype } \\
\hline Luminal A & $108(53.5)$ \\
\hline Luminal B & $51(25.2)$ \\
\hline Her2 & $28(13.9)$ \\
\hline Triple-negative & $15(7.4)$ \\
\hline \multicolumn{2}{|l|}{ Metastatic node status } \\
\hline Positive & $155(76.7)$ \\
\hline Negative & $47(23.3)$ \\
\hline \multicolumn{2}{|l|}{ Metastasis } \\
\hline Yes & 76 (37.6) \\
\hline No & $126(62.4)$ \\
\hline
\end{tabular}

for these assays was assessed in randomly selected samples that were re-genotyped by an independent technician. The concordance among genotype assays was $100 \%$.

Allele and genotype frequencies were estimated by direct counting in both groups. The chi-square test evaluated the Hardy-Weinberg equilibrium (HWE), as well as the differences in the distribution of alleles and genotypes, and the clinical characteristics between patients and controls. To measure the association of breast cancer with the presence of alleles or genotypes, we made stratified analysis by age, smoking status, TNM stage, and histologic-molecular subtype; also, we calculated the odds ratio (OR) and corresponding 95\% confidence intervals (CIs) using SPSS v17.0 software package (SPSS, Inc., Chicago, IL, United States). For all statistical analyzes, $p<0.05$ was considered significant. A Bonferroni correction test was applied to adjust the $p$ values $(p<0.012$ was considered significant). Interaction of the genetic polymorphisms in both loci of each gene was evaluated using the combined effect and the haplotypes analysis. The linkage disequilibrium and the haplotype frequencies were calculated using the Haploview 4.2 software.

\section{RESULTS}

Table 1 shows the clinicopathological characteristics of breast cancer patients. The mean (SD) age observed was $47.9 \pm$ S.D. 7.37 for the breast cancer group and $46.6 \pm$ S.D. 11.7 years in the control group $(p=0.1)$. Results adjusted by the Bonferroni test (0.012) shown that tobacco consumption was marginally associated in the breast cancer group $(p=0.017)$, while alcohol consumption was not associated with breast cancer $(p=0.879)$.

The four analyzed SNPs in the control group were in HardyWeinberg equilibrium (all $p>0.05$ ). Comparative analysis of the AXIN2 and TCF7L2 variants in breast cancer patients and the control group showed significant differences (Table 2). Four different haplotypes were observed in the AXIN2 and TCF7L2 genes, but only the T-T haplotype of the TCF7L2 variants shown statistically significant differences.

The results of demographic, and clinicopathological characteristics for each SNP are shown in Tables 3, 4. Concerning the AXIN2 variants, we did not observe significant differences for the rs1133683 variant when comparing to age, tobacco consumption, TNM stage and histologic molecular subtypes (Table 3). Regarding the TCF7L2 variants, we observed significant differences when comparing the demographic and clinicopathological characteristics between the breast cancer group and the control group (Table 4).

\section{DISCUSSION}

It has been described that genetic alterations in Wnt pathway components, such as APC, $\beta$-catenin, AXIN2, and TCF7L2 are implicated in colorectal, melanoma, gastric, hepatocellular, and breast cancer $(7,8,10-12,37)$. Some reports have shown increased levels of nuclear or cytoplasmic $\beta$-catenin in breast cancer, suggesting activation of the Wnt signaling pathway due to alternative mechanisms such as autocrine signaling or decreased expression of soluble extracellular inhibitors of the Wnt ligand (38-40).

AXIN2 and TCF7L2 are polymorphic genes, and several variants have been identified in their exonic and intronic regions. By the first time, we analyzed genotypes and haplotypes of four SNPs located in genes whose protein products participate in the $\mathrm{Wnt} / \beta$-catenin signaling pathway: $r 1133683(\mathrm{C} / \mathrm{T})$ and $\mathrm{rs} 2240308(\mathrm{C} / \mathrm{T})$ of the AXIN2 gene and rs7903146 $(\mathrm{C} / \mathrm{T})$ and $\mathrm{rs} 12255372(\mathrm{G} / \mathrm{T})$ of the TCF7L2 gene; the results achieved here suggest that the AXIN2 rs2240308 and TCF7L2 rs7903146 and rs12255372 variants play a significant role in promoting breast cancer.

As regards AXIN2 variants, the rs2240308 SNP (c.148 C > T) is a $\mathrm{C}>\mathrm{T}$ nucleotide change at position 148 of the AXIN2 exon 1, which produces a substitution of proline by serine at codon 50 . The variant rs2240308 (p.Pro50Ser) is located near the RGS domain (regulator of G protein signalling; amino acids 81-200), which involves the APC-binding site and participates in the tumor suppressor function of AXIN2 through the assembly of the $\beta$ catenin destruction complex (17-20). We did not find a statistical association of the rs1133683 variant with the demographic and clinicopathological features in these patients. In contrast, patients carrying the $\mathrm{C} / \mathrm{T}$ or $\mathrm{T} / \mathrm{T}$ genotypes of the AXIN2 rs2240308 variant 
TABLE 2 | Genotype, allele and haplotype frequencies of the AXIN2 and TCF7L2 polymorphisms in the breast cancer patients and control group. Numbers in bold represent statistically significant values.

\begin{tabular}{|c|c|c|c|c|}
\hline Genotype & Controls $n=202(\%)$ & $\begin{array}{c}\text { Breast cancer } \\
n=202(\%)\end{array}$ & OR $(95 \% \mathrm{Cl})$ & $p$ value \\
\hline \multicolumn{5}{|c|}{ AXIN2 (rs1133683) } \\
\hline $\mathrm{C} / \mathrm{C}$ & 47 (23.3) & 45 (22.3) & 1.00 (Reference) & \\
\hline $\mathrm{C} / \mathrm{T}$ & $108(53.4)$ & $108(53.4)$ & $1.04(0.64-1.70)$ & 0.960 \\
\hline $\mathrm{T} / \mathrm{T}$ & 47 (23.3) & $49(24.3)$ & 1.08 (0.61-1.92) & 0.884 \\
\hline $\mathrm{C} / \mathrm{T}+\mathrm{T} / \mathrm{T}$ vs. $\mathrm{C} / \mathrm{C}$ & $155(76.7)$ & $157(77.8)$ & 1.05 (0.66-1.68) & 0.905 \\
\hline Allele: C & $202(50.0)$ & $198(49.0)$ & 1.00 (Reference) & \\
\hline $\mathrm{T}$ & $202(50.0)$ & $206(51.0)$ & $1.04(0.78-1.37)$ & 0.832 \\
\hline \multicolumn{5}{|c|}{ AXIN2 (rs2240308) } \\
\hline $\mathrm{C} / \mathrm{C}$ & 74 (36.6) & $38(18.8)$ & 1.00 (Reference) & \\
\hline $\mathrm{C} / \mathrm{T}$ & $103(51.0)$ & $112(55.4)$ & $2.11(1.31-3.40)$ & 0.002 \\
\hline $\mathrm{T} / \mathrm{T}$ & $25(12.4)$ & $52(25.8)$ & $4.05(2.18-7.50)$ & 0.001 \\
\hline $\mathrm{C} / \mathrm{T}+\mathrm{T} / \mathrm{T}$ vs. $\mathrm{C} / \mathrm{C}$ & $128(63.4)$ & $164(81.2)$ & 2.49 (1.58-3.93) & 0.001 \\
\hline Allele: C & $251(62.1)$ & $188(46.5)$ & 1.00 (Reference) & \\
\hline $\mathrm{T}$ & $153(37.9)$ & $216(53.5)$ & $1.88(1.42-2.49)$ & 0.001 \\
\hline \multicolumn{5}{|c|}{ TCF7L2 (rs7903146) } \\
\hline $\mathrm{C} / \mathrm{C}$ & $91(45.1)$ & $62(30.7)$ & 1.00 (Reference) & \\
\hline $\mathrm{C} / \mathrm{T}$ & $94(46.5)$ & $119(58.9)$ & $1.85(1.21-2.83)$ & 0.005 \\
\hline $\mathrm{T} / \mathrm{T}$ & $17(8.4)$ & $21(10.4)$ & $1.81(0.88-3.71)$ & 0.144 \\
\hline $\mathrm{C} / \mathrm{T}+\mathrm{T} / \mathrm{T}$ vs. $\mathrm{C} / \mathrm{C}$ & $111(54.9)$ & $140(69.3)$ & $1.85(1.23-2.78)$ & 0.004 \\
\hline Allele: C & $276(68.3)$ & $243(60.1)$ & 1.00 (Reference) & \\
\hline $\mathrm{T}$ & $128(31.7)$ & $161(39.9)$ & $1.42(1.06-1.90)$ & 0.018 \\
\hline \multicolumn{5}{|c|}{ TCF7L2 (rs12255372) } \\
\hline $\mathrm{G} / \mathrm{G}$ & $119(58.9)$ & $92(45.5)$ & 1.00 (Reference) & \\
\hline $\mathrm{G} / \mathrm{T}$ & $71(35.1)$ & 78 (38.6) & $1.42(0.93-2.16)$ & 0.125 \\
\hline $\mathrm{T} / \mathrm{T}$ & $12(6.0)$ & $32(15.9)$ & 3.44 (1.68-7.06) & 0.001 \\
\hline $\mathrm{G} / \mathrm{T}+\mathrm{T} / \mathrm{T}$ vs. $\mathrm{G} / \mathrm{G}$ & $83(41.0)$ & $110(54.4)$ & $1.71(1.15-2.54)$ & 0.009 \\
\hline Allele: $\mathrm{G}$ & 309 (76.4) & 262 (64.9) & 1.00 (Reference) & \\
\hline $\mathrm{T}$ & $95(23.6)$ & $142(35.1)$ & 1.76 (1.29-2.39) & 0.001 \\
\hline Haplotype & & & & \\
\hline \multicolumn{5}{|c|}{ AXIN2 rs1133683-rs2240308 } \\
\hline $\mathrm{C}-\mathrm{C}$ & $69(34.2)$ & $50(24.8)$ & $0.63(0.41-0.97)$ & 0.049 \\
\hline $\mathrm{T}-\mathrm{T}$ & $44(21.8)$ & $59(29.2)$ & $1.48(0.94-2.32)$ & 0.110 \\
\hline $\mathrm{T}-\mathrm{C}$ & 57 (28.2) & $44(21.8)$ & $0.70(0.45-1.11)$ & 0.167 \\
\hline $\mathrm{C}-\mathrm{T}$ & $32(15.8)$ & $49(24.2)$ & $1.70(1.03-2.79)$ & 0.046 \\
\hline \multicolumn{5}{|c|}{ TCF7L2 rs7903146-rs12255372 } \\
\hline C-G & $110(54.4)$ & $95(47.0)$ & $0.74(0.50-1.09)$ & 0.163 \\
\hline $\mathrm{T}-\mathrm{G}$ & $44(21.8)$ & $36(17.8)$ & $0.77(0.47-1.27)$ & 0.382 \\
\hline $\mathrm{T}-\mathrm{T}$ & $20(10.0)$ & $44(21.8)$ & $2.53(1.43-4.48)$ & 0.001 \\
\hline C-T & 28 (13.8) & 27 (13.4) & $0.95(0.54-1.69)$ & 1.000 \\
\hline
\end{tabular}

$\mathrm{p}$ values were adjusted by the Bonferroni test (0.012).

present an increased association regarding age, advanced TNM stages, and positive Her2 subtype of the patients. Wang et al. analyzed the rs2240308 SNP in peripheral blood mononuclear cells of breast cancer patients from North America (22), but no association was found. On the contrary, our results and those described by Aristazabal-Pachon et al. (20) showed that patients who were carriers of the T allele (CT or TT genotypes) had a greater tendency to develop breast cancer. In addition, an association of the CT or TT genotypes of the rs2240308 variant was found with some clinicopathological variables such as TNM stage and histological-molecular subtype. Interestingly, Wang et al. examined the AXIN2 rs4791171 variant and reported a significant risk in younger patients with breast cancer (22); meanwhile,
Alanazi et al. examined the AXIN2 rs3923086 variant and found a significant protective association for breast cancer in younger patients who also had the negative estrogen receptor subtype (21). To our knowledge, this is the second study reporting the association of the rs2240308 variant with breast cancer risk. Neither association was found with the haplotypes of these polymorphisms.

As regards TCF7L2 variants, several studies have shown an association between some TCF7L2 variants with different types of cancer $(24,26,29-32,41)$, which is explained because the TCF4 protein, involved in the $\mathrm{Wnt} / \beta$-catenin signaling pathway, acts as a transcription factor that induces expression of some oncogenes as CCND1 and $M Y C$, involved in proliferation, apoptosis, 
TABLE 3 | Association of AXIN2 genotypes with clinical characteristics of breast cancer. Numbers in bold represent statistically significant values.

\begin{tabular}{|c|c|c|c|c|c|c|}
\hline \multirow[t]{2}{*}{ Variable } & \multicolumn{3}{|c|}{ Control/Breast cancer } & \multicolumn{3}{|c|}{ OR $(95 \% \mathrm{Cl}) ; p$ value } \\
\hline & CC & CT & TT & CT versus $\mathbf{C C}$ & TT versus $\mathbf{C C}$ & $\mathbf{C T}+\mathbf{T T}$ versus $\mathbf{C C}$ \\
\hline \multicolumn{7}{|c|}{ AXIN2 rs1133683 } \\
\hline \multicolumn{7}{|l|}{ Age (years) } \\
\hline$<50$ & $24 / 20$ & $67 / 57$ & $28 / 24$ & $1.02(0.51-2.03) ; 1.000$ & $1.02(0.45-2.30) ; 1.000$ & $1.02(0.52-1.98) ; 1.000$ \\
\hline$\geq 50$ & $23 / 25$ & $41 / 51$ & $19 / 25$ & 1.14 (0.56-2.30); 0.842 & $1.21(0.53-2.75) ; 0.805$ & 1.16 (0.60-2.25); 0.774 \\
\hline Smoker & $8 / 13$ & $14 / 26$ & $8 / 11$ & $1.14(0.38-3.41) ; 1.000$ & 0.84 (0.23-3.00); 1.000 & $1.03(0.37-2.88) ; 1.000$ \\
\hline \multicolumn{7}{|l|}{ TNM Stage } \\
\hline Stage I + II & $47 / 15$ & $108 / 38$ & $47 / 17$ & 1.10 (0.55-2.19); 0.917 & 1.13 (0.50-2.53); 0.919 & $1.11(0.57-2.14) ; 0.880$ \\
\hline Stage III + IV & $47 / 30$ & $108 / 70$ & $47 / 32$ & $1.01(0.58-1.75) ; 1.000$ & 1.06 (0.56-2.02); 0.973 & $1.03(0.61-1.73) ; 1.000$ \\
\hline Stage IV & $47 / 16$ & $108 / 36$ & $47 / 20$ & 0.97 (0.49-1.93); 1.000 & 1.25 (0.57-2.70); 0.710 & 1.06 (0.55-2.02); 0.985 \\
\hline \multicolumn{7}{|c|}{ Histologic molecular subtypes } \\
\hline Luminal A & $47 / 27$ & $108 / 53$ & $47 / 28$ & 0.85 (0.48-1.52); 0.698 & $1.03(0.53-2.01) ; 1.000$ & 0.90 (0.52-1.56); 0.840 \\
\hline Luminal B & $47 / 12$ & $108 / 27$ & $47 / 12$ & 0.97 (0.45-2.09); 1.000 & 1.00 (0.40-2.45); 1.000 & $0.98(0.47-2.03) ; 1.000$ \\
\hline Her2 & $47 / 3$ & $108 / 19$ & $47 / 6$ & 2.75 (0.77-9.76); 0.169 & 2.00 (0.47-8.47); 0.544 & 2.62 (0.73-8.74); 0.205 \\
\hline Triple Negative & $47 / 3$ & $108 / 9$ & $47 / 3$ & 1.30 (0.33-5.04); 0.951 & $1.00(0.19-5.21) ; 1.000$ & $1.21(0.32-4.47) ; 1.000$ \\
\hline \multicolumn{7}{|c|}{ AXIN2 rs2240308 } \\
\hline \multicolumn{7}{|l|}{ Age (years) } \\
\hline$<50$ & $43 / 20$ & $63 / 58$ & $13 / 23$ & 1.97 (1.04-3.75); 0.051 & 3.80 (1.60-9.01); 0.003 & 2.00 (1.07-3.73); 0.038 \\
\hline$\geq 50$ & $31 / 18$ & $40 / 54$ & $12 / 29$ & 2.32 (1.14-4.73); 0.029 & 4.16 (1.71-10.12); 0.002 & 2.74 (1.39-5.40); 0.004 \\
\hline Smoker & $15 / 11$ & $11 / 29$ & $4 / 10$ & 3.59 (1.26-10.19); 0.028 & 3.40 (0.84-13.77); 0.153 & 3.54 (1.33-9.44); 0.019 \\
\hline \multicolumn{7}{|l|}{ TNM Stage } \\
\hline Stage I + II & $74 / 13$ & $103 / 37$ & $25 / 20$ & 2.04 (1.01-4.11); 0.062 & 4.55 (1.98-10.47); 0.001 & 2.53 (1.30-4.93); 0.008 \\
\hline Stage III + IV & $74 / 25$ & $103 / 75$ & $25 / 32$ & 2.15 (1.25-3.70); 0.007 & 3.78 (1.89-7.57); 0.001 & 2.47 (1.46-4.16); 0.001 \\
\hline Stage IV & $74 / 11$ & $103 / 38$ & $25 / 23$ & $2.48(1.19-5.17) ; 0.020$ & 6.18 (2.64-14.47); 0.001 & 3.20 (1.58-6.47); 0.001 \\
\hline \multicolumn{7}{|c|}{ Histologic molecular subtypes } \\
\hline Luminal A & $74 / 25$ & $103 / 55$ & $25 / 28$ & 1.58 (0.90-2.76); 0.141 & 3.31 (1.63-6.70); 0.001 & 1.91 (1.12-3.26); 0.021 \\
\hline Luminal B & $74 / 7$ & $103 / 35$ & $25 / 9$ & 3.59 (1.51-8.52); 0.004 & 3.80 (1.28-11.28); 0.026 & 3.63 (1.55-8.47); 0.003 \\
\hline Her2 & $74 / 2$ & $103 / 16$ & $25 / 10$ & 5.74 (1.28-25.85); 0.021 & 14.8 (3.03-72.17); 0.001 & 10.4 (2.43-44.46); 0.001 \\
\hline Triple Negative & $74 / 4$ & $103 / 6$ & $25 / 5$ & 1.07 (0.29-3.95); 1.000 & 3.70 (0.92-14.86); 0.120 & $1.58(0.48-5.17) ; 0.618$ \\
\hline
\end{tabular}

$p$ values were adjusted by the Bonferroni test (0.012).

invasion, and metastasis $(9,40)$. It has been described that the most frequent TCF7L2 variants (rs7903146, intron 3 and rs12255372, intron 4) affect the mRNA stability and the alternative splicing $(24,26)$. Specifically, in breast cancer, these TCF7L2 variants (rs12255372 and rs7903146) shown results contradictories regards to cancer susceptibility (21, 29, 31-34, 41). In this study, we found an association of the genotypes CT and TT of both variants with breast cancer risk. Patients carrying the C/T heterozygous genotype of the variant rs7903146 showed a significant risk to develop breast cancer, including in younger patients ( $<50$ years). Likewise, patients carrying the homozygous T/T genotype of the TCF7L2 rs12255372 variant showed a significant association with breast cancer and with the possibility of reach the advanced TNM stages III + IV. These patients also exhibited an increased risk to develop luminal B tumors. The haplotype analysis found that patients carrying the T-T haplotype (rs7903146 and rs12255372 SNPs) show increased breast cancer frequency. In brief, our results found a higher cancer risk for women carrying the CT genotype compared to women carrying the GG genotype of the TCF7L2 7903146 variant. This association was also statistically significant for patients under 50 years of age and with tumors in advanced
TNM stages (III + IV). The frequencies discrepancies observed between our study and other studies could be related to population differences, ethnic diversity, sample size, and different histologically tumors.

In conclusion, our study shows that the $\mathrm{C} / \mathrm{T}$ and $\mathrm{T} / \mathrm{T}$ genotypes of the AXIN2 rs2240308 variant and the TCF7L2 rs7903146 $\mathrm{C} / \mathrm{T}$ and $\mathrm{rs} 12255372 \mathrm{~T} / \mathrm{T}$ genotypes are linked to breast cancer. Furthermore, some genotypes are also significantly associated with advanced stages of TNM, the histology-molecular subtypes of breast cancer, and the age of the patients. Additional studies, including larger samples and functional analysis of the polymorphisms, are necessary to confirm and extend our findings. We speculate that these gene variants may be important in the pathogenesis and/or susceptibility to this disease.

\section{SUMMARY TABLE}

\section{What Is Known About This Subject}

- Mutations or genetic polymorphisms in the TCF7L2 and AXIN2 genes have been associated with different cancers. 
TABLE 4 | Association of TCF7L2 genotypes with clinical characteristics of breast cancer. Numbers in bold represent statistically significant values.

\begin{tabular}{|c|c|c|c|c|c|c|}
\hline \multirow[b]{3}{*}{ Characteristic } & \multicolumn{5}{|c|}{ TCF7L2 (rs7903146) } & \\
\hline & \multicolumn{3}{|c|}{ Control/Breast cancer } & \multicolumn{3}{|c|}{ OR $(95 \% \mathrm{Cl}) ; p$ value } \\
\hline & CC & Ст & $\mathrm{TT}$ & $\mathrm{CT}$ versus $\mathrm{CC}$ & TT versus $\mathbf{C C}$ & $\mathrm{CT}+\mathrm{TT}$ versus $\mathrm{CC}$ \\
\hline \multicolumn{7}{|l|}{ Age (years) } \\
\hline$<50$ & $56 / 28$ & $53 / 61$ & $10 / 12$ & 2.30 (1.28-4.12); 0.007 & 2.40 (0.92-6.23); 0.114 & 2.31 (1.31-4.07); 0.005 \\
\hline$\geq 50$ & $35 / 34$ & $41 / 58$ & $7 / 9$ & 1.45 (0.78-2.70); 0.300 & $1.32(0.44-3.95) ; 0.821$ & 1.43 (0.78-2.61); 0.301 \\
\hline Smoker & $11 / 10$ & $17 / 33$ & $2 / 7$ & $2.13(0.75-6.02) ; 0.237$ & 3.85 (0.64-23.05); 0.260 & 2.31 (0.83-6.39); 0.168 \\
\hline \multicolumn{7}{|l|}{ TNM Stage } \\
\hline Stage | + II & $91 / 21$ & $94 / 41$ & $17 / 8$ & 1.89 (1.03-3.44); 0.051 & $2.03(0.77-5.35) ; 0.231$ & 1.91 (1.06-3.42); 0.039 \\
\hline Stage III + IV & $91 / 41$ & $94 / 78$ & $17 / 13$ & 1.84 (1.14-2.96); 0.015 & 1.69 (0.75-3.81); 0.283 & 1.81 (1.14-2.88); 0.04 \\
\hline Stage IV & $91 / 20$ & $94 / 45$ & $17 / 7$ & 2.17 (1.19-3.97); 0.015 & $1.87(0.68-5.11) ; 0.338$ & 2.13 (1.18-3.82); 0.015 \\
\hline \multicolumn{7}{|c|}{ Histologic molecular subtypes } \\
\hline Luminal A & $91 / 36$ & $94 / 64$ & $17 / 8$ & 1.72 (1.04-2.83); 0.044 & 1.18 (0.47-2.99); 0.898 & 1.63 (1.00-2.66); 0.060 \\
\hline Luminal B & $91 / 13$ & $94 / 31$ & $17 / 7$ & 2.30 (1.13-4.69); 0.028 & 2.88 (1.00-8.27); 0.086 & 2.39 (1.20-4.76); 0.017 \\
\hline Her2 & $91 / 7$ & $94 / 17$ & $17 / 4$ & 2.35 (0.93-5.93); 0.102 & 3.05 (0.80-11.60); 0.195 & 2.45 (1.00-6.04); 0.070 \\
\hline Triple Negative & $91 / 6$ & $94 / 7$ & $17 / 2$ & $1.12(0.36-3.48) ; 1.000$ & 1.78 (0.33-9.59); 0.851 & $1.22(0.42-3.58) ; 0.912$ \\
\hline \multicolumn{7}{|c|}{ TCF7L2 (rs12255372) } \\
\hline & \multicolumn{3}{|c|}{ Control/Breast cancer } & \multicolumn{3}{|c|}{ OR $(95 \% \mathrm{Cl}) ; p$ value } \\
\hline Variable & GG & GT & TT & GT versus $\mathbf{G G}$ & TT versus GG & $\mathbf{G T}+\mathbf{T T}$ versus $\mathbf{G G}$ \\
\hline \multicolumn{7}{|l|}{ Age (years) } \\
\hline$<50$ & $77 / 75$ & $35 / 42$ & $7 / 14$ & 2.05 (1.14-3.66); 0.021 & 3.42 (1.28-9.10); 0.020 & 2.28 (1.32-3.92); 0.004 \\
\hline$\geq 50$ & $42 / 47$ & $36 / 36$ & $5 / 18$ & 0.89 (0.47-1.66); 0.844 & 3.21 (1.09-9.42); 0.049 & 1.17 (0.65-2.10); 0.688 \\
\hline Smoker & $21 / 20$ & $8 / 22$ & $1 / 8$ & $2.88(1.04-7.96) ; 0.066$ & 8.40 (0.96-73.36); 0.068 & 3.50 (1.33-9.18); 0.017 \\
\hline \multicolumn{7}{|l|}{ TNM Stage } \\
\hline Stage I + II & $119 / 36$ & $71 / 25$ & $12 / 9$ & 1.16 (0.64-2.09); 0.723 & 2.47 (0.96-6.35); 0.095 & 1.35 (0.78-2.33); 0.342 \\
\hline Stage III + IV & $119 / 56$ & $71 / 53$ & $12 / 23$ & 1.58 (0.98-2.55); 0.075 & 4.07 (1.89-8.76); 0.001 & 1.94 (1.24-3.03); 0.004 \\
\hline Stage IV & $119 / 27$ & $71 / 34$ & $12 / 11$ & $2.11(1.17-3.78) ; 0.017$ & 4.04 (1.61-10.12); 0.004 & 2.38 (1.37-4.15); 0.002 \\
\hline \multicolumn{7}{|c|}{ Histologic molecular subtypes } \\
\hline Luminal A & $119 / 53$ & $71 / 43$ & $12 / 12$ & 1.35 (0.82-2.23); 0.278 & 2.24 (0.94-5.32); 0.101 & 1.48 (0.92-2.38); 0.123 \\
\hline Luminal B & $119 / 17$ & $71 / 20$ & $12 / 14$ & 1.97 (0.96-4.01); 0.087 & 8.16 (3.24-20.56); 0.001 & 2.86 (1.50-5.47); 0.001 \\
\hline Her2 & $119 / 15$ & $71 / 8$ & $12 / 5$ & $0.89(0.36-2.21) ; 0.988$ & 3.30 (1.02-10.68); 0.087 & $1.24(0.56-2.74) ; 0.739$ \\
\hline Triple Negative & $119 / 7$ & $71 / 7$ & $12 / 1$ & 1.67 (0.56-4.97); 0.513 & $1.41(0.16-12.50) ; 1.000$ & 1.63 (0.57-4.69); 0.511 \\
\hline
\end{tabular}

p values were adjusted by the Bonferroni test (0.012).

- Axin2 protein participates as a negative regulator of the $\mathrm{Wnt} / \beta$-catenin pathway with a crucial role in cell differentiation, migration, and apoptosis.

- The transcription factor 7-like 2 is involved in cell differentiation and migration.

\section{What This Paper Adds}

- Frequencies of the CT and TT genotypes of the AXIN2 rs2240308 variant are significantly higher in breast cancer patients. These same genotypes were associated with advanced TNM stages and histologic molecular subtypes in breast cancer patients.

- Frequencies of the CT or GT and TT genotypes of the TCF7L2 rs7903146 and rs12255372 variants are significantly higher in breast cancer patients. These genotypes were also associated with age, advanced TNM stages and histologic molecular subtypes in breast cancer patients.

\section{DATA AVAILABILITY STATEMENT}

The original contributions presented in the study are included in the article/supplementary material, further inquiries can be directed to the corresponding author.

\section{ETHICS STATEMENT}

The study was approved by the Ethical Committee 1305 (R-20181305-004) of West Biomedical Research Center, IMSS, and conducted according to national and international ethical standards. All the participants signed informed consent for participation in this study.

\section{AUTHOR CONTRIBUTIONS}

Study conception or design: MR-R and PB-N; Data Processing, Collection, Perform Experiments: VR-E, AS-S, MP-C, and CJ-V; Data analyzing and draft manuscript preparation: VR-E, AS-S, 
MP-C, and SF-M; Supervision, Funding Acquisition: MR-R; Critical Revision or Editing of the Article: MR-R, PB-N, MG-A, ESG, SF-M, and JS-C; Final Approval of the version to be published: VR-E, AS-S, MP-C, MG-A, ES-G, PB-N, CJ-V, SF-M, JS-C, and MR-R.

\section{FUNDING}

This project was not supported by specific subsidies, but it had reagents and equipment from the laboratories of the Center for Biomedical Research of the Mexican Institute of Social Security.

\section{REFERENCES}

1. World Health Organization. Breast Cancer (2021). Available at: https://www. who.int/news-room/fact-sheets/detail/breast-cancer. (Accessed April 10, 2021).

2. Bray F, Ferlay J, Soerjomataram I, Siegel RL, Torre LA, Jemal A. Global Cancer Statistics 2018: GLOBOCAN Estimates of Incidence and Mortality Worldwide for 36 Cancers in 185 Countries. CA: A Cancer J Clinicians (2018) 68:394-424. doi:10.3322/caac. 21492

3. McPherson K, Steel CM, Dixon JM. ABC of Breast Diseases: Breast Cancerepidemiology, risk factors, and genetics. BMJ (2000) 321:624-8. doi:10.1136/ bmj.321.7261.624

4. Angahar LT. An overview of breast cancer epidemiology, risk factors, pathophysiology, and cancer risks reduction. MOJ Biol Med (2017) 1:92-6. doi:10.15406/mojbm.2017.01.00019

5. Lynch JA, Venne V, Berse B. Genetic tests to identify risk for breast cancer. Semin Oncol Nurs (2015) 31:100-7. doi:10.1016/j.soncn.2015.02.007

6. Zhang B, Beeghly-Fadiel A, Long J, Zheng W. Genetic variants associated with breast-cancer risk: comprehensive research synopsis, meta-analysis, and epidemiological evidence. Lancet Oncol (2011) 12:477-88. doi:10.1016/ s1470-2045(11)70076-6

7. Wellenstein MD, Coffelt SB, Duits DEM, van Miltenburg MH, Slagter M, de Rink I, et al. Loss of p53 triggers WNT-dependent systemic inflammation to drive breast cancer metastasis. Nature (2019) 572:538-42. doi:10.1038/s41586019-1450-6

8. Nusse R, Clevers H. Wnt/ $\beta$-Catenin Signaling, Disease, and Emerging Therapeutic Modalities. Cell (2017) 169:985-99. doi:10.1016/j.cell.2017.05.016

9. Koni M, Pinnarò V, Brizzi MF. The Wnt Signalling Pathway: A Tailored Target in Cancer. Ijms (2020) 21:7697. doi:10.3390/ijms21207697

10. Herbst A, Jurinovic V, Krebs S, Thieme SE, Blum H, Göke B, et al. Comprehensive analysis of $\beta$-catenin target genes in colorectal carcinoma cell lines with deregulated Wnt/ $\beta$-catenin signaling. BMC Genomics (2014) 15 : 74. doi:10.1186/1471-2164-15-74

11. Katoh M. Canonical and non-canonical WNT signaling in cancer stem cells and their niches: Cellular heterogeneity, omics reprogramming, targeted therapy and tumor plasticity (Review). Int J Oncol (2017) 51:1357-69. doi:10.3892/ijo.2017.4129

12. Lustig B, Jerchow B, Sachs M, Weiler S, Pietsch T, Karsten U, et al. Negative feedback loop of Wnt signaling through upregulation of conductin/axin2 in colorectal and liver tumors. Mol Cel Biol (2002) 22:1184-93. doi:10.1128/ mcb.22.4.1184-1193.2002

13. Mukherjee N, Panda CK. Wnt/ $\beta$-Catenin Signaling Pathway as Chemotherapeutic Target in Breast Cancer: An Update on Pros and Cons. Clin Breast Cancer (2020) 20:361-70. doi:10.1016/j.clbc.2020.04.004

14. Mulholland DJ, Dedhar S, Coetzee GA, Nelson CC. Interaction of Nuclear Receptors with the Wnt/ $\beta$-Catenin/Tcf Signaling Axis: Wnt You Like to Know? Endocr Rev (2005) 26:898-915. doi:10.1210/er.2003-0034

15. Rosales-Reynoso MA, Arredondo-Valdez AR, Wence-Chávez LI, BarrosNúñez P, Gallegos-Arreola MP, Flores-Martínez SE, et al. AXIN2 Polymorphisms and Their Association with Colorectal Cancer in Mexican Patients. Genet Test Mol Biomarkers (2016) 20:438-44. doi:10.1089/ gtmb.2016.0026

\section{CONFLICT OF INTEREST}

The authors declare that the research was conducted in the absence of any commercial or financial relationship that could be construed as a potential conflict of interest.

\section{ACKNOWLEDGMENTS}

We thank all patients and controls for their participation in this study.

16. Otero L, Lacunza E, Vasquez V, Arbelaez V, Cardier F, González F. Variations in AXIN2 predict risk and prognosis of colorectal cancer. BDJ Open (2019) 5: 13. doi:10.1038/s41405-019-0022-z

17. Liu D, Li L, Yang Y, Liu W, Wu J. The Axin2 rs2240308 polymorphism and susceptibility to lung cancer in a Chinese population. Tumor Biol (2014) 35: 10987-91. doi:10.1007/s13277-014-2399-6

18. Gunes EG, Pinarbasi E, Pinarbasi H, Silig Y. Strong association between lung cancer and the AXIN2 polymorphism. Mol Med Rep (2009) 2:1029-35. doi:10.3892/mmr_00000210

19. Ma C, Liu C, Huang P, Kaku H, Chen J, Guo K, et al. Significant association between the Axin2 rs2240308 single nucleotide polymorphism and the incidence of prostate cancer. Oncol Lett (2014) 8:789-94. doi:10.3892/ ol.2014.2177

20. Aristizabal-Pachon AF, Carvalho TI, Carrara HH, Andrade J, Takahashi CS. AXIN2 Polymorphisms, the $\beta$-Catenin Destruction Complex Expression Profile and Breast Cancer Susceptibility. Asian Pac J Cancer Prev (2015) 16:7277-84. doi:10.7314/apjcp.2015.16.16.7277

21. Alanazi MS, Parine NR, Shaik JP, Alabdulkarim HA, Ajaj SA, Khan Z. Association of single nucleotide polymorphisms in Wnt signaling pathway genes with breast cancer in Saudi patients. PLoS One (2013) 8:e59555 doi:10.1371/journal.pone.0059555

22. Wang X, Goode EL, Fredericksen ZS, Vierkant RA, Pankratz VS, Liu-Mares W, et al. Association of Genetic Variation in Genes Implicated in the $\beta$-Catenin Destruction Complex with Risk of Breast Cancer. Cancer Epidemiol Biomarkers Prev (2008) 17:2101-8. doi:10.1158/1055-9965.epi-08-0134

23. Dai J, Gao H, Xue J, Lin W, Zheng L. The Association Between AXIN2 Gene Polymorphisms and the Risk of Breast Cancer in Chinese Women. Genet Test Mol Biomarkers (2019) 23:393-400. doi:10.1089/gtmb.2018.0309

24. Folsom AR, Pankow JS, Peacock JM, Bielinski SJ, Heiss G, Boerwinkle E. Variation in TCF7L2 and Increased Risk of Colon Cancer. Diabetes Care (2008) 31:905-9. doi:10.2337/dc07-2131

25. Hazra A, Fuchs CS, Chan AT, Giovannucci EL, Hunter DJ. Association of the TCF7L2 polymorphism with colorectal cancer and adenoma risk. Cancer Causes Control (2008) 19:975-80. doi:10.1007/s10552-008-9164-3

26. Slattery ML, Folsom AR, Wolff R, Herrick J, Caan BJ, Potter JD. Transcription factor 7-like 2 polymorphism and colon cancer. Cancer Epidemiol Biomarkers Prev (2008) 17:978-82. doi:10.1158/1055-9965.epi-07-2687

27. Shim H-J, Lee R, Shin M-H, Kim H-N, Kweon S-S. Association between the TCF7L2 polymorphism and colorectal cancer does Not differ by diabetes and obesity statuses. Cancer Epidemiol (2016) 45:108-11. doi:10.1016/ j.canep.2016.10.012

28. Rosales-Reynoso MA, Arredondo-Valdez AR, Juárez-Vázquez CI, WenceChavez LI, Barros-Núñez P, Gallegos-Arreola MP, et al. TCF7L2 and CCND1 polymorphisms and its association with colorectal cancer in Mexican patients. Cel Mol Biol (Noisy-le-grand) (2016) 62:13-20. ISSN: 1165 158X (Electronic).

29. Machiela MJ, Lindstrom S, Allen NE, Haiman CA, Albanes D, Barricarte A, et al. Association of type 2 diabetes susceptibility variants with advanced prostate cancer risk in the Breast and Prostate Cancer Cohort Consortium. Am J Epidemiol (2012) 176:1121-9. doi:10.1093/aje/kws191

30. Rice SJ, Liu X, Hyland V, Liu Z, Belani CP. Mutations in genes connected with the TCF7L2 transcription factor are associated with a poor prognosis in nonsmall cell lung cancer. Lung Cancer (2020) 141:97-100. doi:10.1016/ j.lungcan.2020.01.015 
31. Naidu R, Yip CH, Taib NAM. Genetic variations in transcription factor 7-like 2 (TCF7L2) gene: association of TCF7L2 rs12255372(G/T) or rs7903146(C/T) with breast cancer risk and clinico-pathological parameters. Med Oncol (2012) 29:411-7. doi:10.1007/s12032-011-9837-8

32. Connor AE, Baumgartner RN, Baumgartner KB, Kerber RA, Pinkston C, John EM, et al. Associations between TCF7L2 polymorphisms and risk of breast cancer among Hispanic and non-Hispanic white women: the Breast Cancer Health Disparities Study. Breast Cancer Res Treat (2012) 136:593-602. doi:10.1007/s10549-012-2299-7

33. Min W, Liu X, Lu Y, Gong Z, Wang M, Lin S, et al. Association of transcription factor 7-like 2 gene polymorphisms with breast cancer risk in northwest Chinese women. Oncotarget (2016) 7:77175-82. doi:10.18632/ oncotarget.12591

34. Zhao Z, Wen W, Michailidou K, Bolla MK, Wang Q, Zhang B, et al. Association of genetic susceptibility variants for type 2 diabetes with breast cancer risk in women of European ancestry. Cancer Causes Control (2016) 27: 679-93. doi:10.1007/s10552-016-0741-6

35. Miller SA, Dykes DD, Polesky HF. A simple salting out procedure for extracting DNA from human nucleated cells. Nucl Acids Res (1988) 16: 1215. doi:10.1093/nar/16.3.1215

36. Bodhini D, Radha V, Dhar M, Narayani N, Mohan V. The rs12255372(G/T) and rs7903146(C/T) polymorphisms of the TCF7L2 gene are associated with type 2 diabetes mellitus in Asian Indians. Metabolism (2007) 56:1174-8. doi:10.1016/j.metabol.2007.04.012
37. Sarrió D, Moreno-Bueno G, Hardisson D, Sánchez-Estévez C, Guo M, Herman JG, et al. Epigenetic and genetic alterations of APC and CDH1 genes in lobular breast cancer: relationships with abnormal E-cadherin and catenin expression and microsatellite instability. Int J Cancer (2003) 106:208-15. doi:10.1002/ijc.11197

38. Bafico A, Liu G, Goldin L, Harris V, Aaronson SA. An autocrine mechanism for constitutive Wnt pathway activation in human cancer cells. Cancer Cell (2004) 6:497-506. doi:10.1016/j.ccr.2004.09.032

39. Prunier C, Hocevar BA, Howe PH. Wnt signaling: physiology and pathology. Growth Factors (2004) 22:141-50. doi:10.1080/08977190410001720860

40. Zhong Z, Yu J, Virshup DM, Madan B. Wnts and the hallmarks of cancer. Cancer Metastasis Rev (2020) 39:625-45. doi:10.1007/s10555-020-09887-6

41. Burwinkel B, Shanmugam KS, Hemminki K, Meindl A, Schmutzler RK, Sutter C, et al. Transcription factor 7-like 2 (TCF7L2) variant is associated with familial breast cancer risk: a case-control study. BMC Cancer (2006) 6:268. doi:10.1186/1471-2407-6-268

Copyright (c) 2022 Rosales-Reynoso, Rosas-Enríquez, Saucedo-Sariñana, PérezCoria, Gallegos-Arreola, Salas-González, Barros-Núñez, Juárez-Vázquez, FloresMartinez and Sánchez-Corona. This is an open-access article distributed under the terms of the Creative Commons Attribution License (CC BY). The use, distribution or reproduction in other forums is permitted, provided the original author(s) and the copyright owner(s) are credited and that the original publication in this journal is cited, in accordance with accepted academic practice. No use, distribution or reproduction is permitted which does not comply with these terms. 